\title{
MEMBANGUN WEBSITE SEBAGAI MEDIA RESERVASI OBJECT WISATA MENGGUNAKAN METODE APRORI
}

\author{
Eddi Kurniyadi ${ }^{1}$, Agus Sujarwadi ${ }^{2}$ \\ ${ }^{1,2}$ Teknik Informatika, Universitas Teknologi Yogyakarta \\ 1,2 Jl.siliwangi (Ringroud Utara),Jombor,Yogyakarta \\ 11Eddikurniyadi90@gmail.com, 2agus.sujarwadi@uty.ac.id
}

\begin{abstract}
With the growing of information technology and internet. The Lombok Travel is one of the few journeys in the development of the system. Currently, there are also manual transactions. In addition, the packages for tourist destinations are usually set based on the packages that have been made the trip, but also the ordering system that is online in order for members in ordering transactions. Aprioriic method to display the most popular tour packages or tour packages most in the message by previous customers. For the application of this method will be made based website system. The results of this study are Applications that use Apriori Method to display the most popular tour packages, tour packages, travel destinations, price packages, package messages and members can directly place an order package on a system that can be accessed online.
\end{abstract}

Keywords : Information Technology, Response System, Apriori.

\begin{abstract}
Abstrak
Dengan semakin berkembangnya teknologi informasi dan internet. The Lombok Travel termasuk salah satu travel yang masih kurang dalam pengembangan sistem. Saat ini, apabila ada transaksi pemesanan masih dilakukan secara manual. Selain itu paket-paket untuk destinasi wisata biasanya sudah di tentukan berdasarkan paket-paket yang sudah disediakan pihak travel, Sehingga dibutuhkan suatu sistem reservasi yang sudah online agar memudahkan member dalam melakukan transaksi pemesanan. Metode Apriori digunakan untuk menampilkan paket wisata terpopular atau paket wisata yang paling banyak di pesan oleh pelanggan sebelumnya. Untuk penerapan metode ini akan dibuat suatu sistem berbasis website. Hasil dari penelitian ini adalah suatu Aplikasi reservasi yang menggunakan Metode Apriori untuk menampilkan paket wisata yang paling popular, paket tour, tujuan wisata, harga paket, pesan paket dan member bisa langsung melakukan pemesanan paket tour pada sistem karena sistem sudah bisa diakses secara online.
\end{abstract}

Kata kunci : Teknologi informasi, Sistem Resevasi, Apriori, 


\section{Pendahuluan}

Saat ini banyak sekali perusahaan yang bergerak dalam bidang jasa transportasi salah satunya adalah biro perjalanan tour atau yang biasa disebut dengan travel. The Lombok Travel adalah salah satu biro perjalan tour yang ada di Lombok. The Lombok Travel ini sudah berpengalaman di banyak industri bisnis pariwisata dan perjalanan dengan semakin berkembangnya teknologi informasi dan internet, The Lombok Travel termasuk salah satu travel yang masih kurang dalam pengembangan sistem. Saat ini, apabila ada transaksi pemesanan perjalanan masih dilakukan secara manual. Pelanggan diharuskan mengisi formulir pemesanan secara manual yang akan dikirim melalui email oleh agen travel. Selain itu paket-paket untuk destinasi wisata biasanya sudah di tentukan berdasarkan paket-paket yang sudah disediakan pihak travel, padahal pihak travel tidak akan keberatan apabila pemesanan ingin melakukan perubahan destinasi sesuai yang diinginkan.

Berdasarkan permasalahan diatas, perlu adanya pengembangan sistem informasi untuk reservasi object wisata. Dimana sistem ini akan mempermudah pemilihan paket ataupun agenda tujuan wisata selama berada di lombok, hal ini juga mempermudah petugas untuk mengolah data-data transaksi yang ada.

Sistem informasi reservasi object wisata pada The Lombok Travel ini nantinya akan memiliki fitur-fitur seperti pengadaan paket wisata yang sudah di tentukan oleh pihak travel, pemilihan akomodasi dan objek wisata sendiri oleh customer sesuai jumlah hari yang diinginkan, konsultasi kebutuhan waktu dan biaya untuk objek wisata yang dipilih.

Sesuai dengan uraian diatas, dalam penelitian ini penulis tertarik untuk membuatkan website dengan memberikan judul “Membangun Website Sebagai Media Reservasi Objek Wisata di Daerah Pulau Lombok (Studi kasus The Lombok Travel Mataram)" yang beralamat di Jl. Dr. Soedjono Lingkar Permai Blok R7, Kelurahan Tanjung Karang Kec. Sekarbela, Tanjung Karang, Sekarbela, Mataram.

Berdasakan pada latar belakang masalah yang telah diungkapkan sebelumnya, maka rumusan masalah yang di ambil adalah bagaimana merancang dan membangun website sebagai media promosi dan reservasi objek wisata yang ada di pulau lombok, dengan adanya website tersebut diharapkan dapat mempermudah petugas dalam mengolah data pemesanan objek wisata.

Agar permasalahan ini tidak terlalu luas maka penulis membatasi permasalahan yang ada. Hal ini bertujuan agar pemecahan masalah tersebut dapat lebihterarah.

Adapun batasan masalah ini yaitu :

a. Sistem sebagai media reservasi paket wisata yang ada di pulau lombok.

b. Sistem berbasis website ini memberikan informasi objek wisata terbaik dan acaraacara yang ada di lombok.

c. Administrator dapat melakukan pengolahan data admin, data member, data objek wisata dan data pemesanan paket wisata.

d. Sistem pembayaran dilakukan secara transfer dengan tambahan pembayaran sebesar 3 digit yang di ambil dari kode pemesanan agar mempermudah dalam proses konfirmasi.

e. Notifikasi pemesanan akan dikirim lewat email dan sms.

Adapun tujuan penulis dalam mengadakan penilitian ini adalah sebagai berikut :

a. Memanfaatkan media internet untuk memperluas area pemasaran The Lombok Travel.

b. Memanfaatkan media internet agarpromosi dan pemesanan paket wisata The Lombok Travel meningkat.

c. Menghasilkan sistem yang mampu mengelola data reservasi secara online.

Adapun manfaat dari hasil penelitian ini adalah

a. Memberikan kemudahan dalam mempromosikan objek wisata lombok.

b. Memperluas area pemasaran karena sudah menggunakan internet marketing.

c. Meningkatkan pendapatan The Lombok Travel karena area pemasaran menjadi lebih luas.

d. Mempermudah dalam mendapatkan informasi objek wisata terbaik yang ada di lombok.

e. Dapat melakukan custome objek wisata yang diinginkan atapun melakukan konsultasi jumlah biaya dan waktu untuk objek wisata yang diinginkan.

f. Mempermudah dalam melakukan reservasi paket wisata, serta pembayaran bisa di lakukan secara transfer lewat ATM. 


\section{Tinjuan Pustaka}

Dalam penelitian ini penulis meninjau hasilhasil penelitian yang pernah ada sebelumnya. Penelitian-penelitian yang ditinjau antara lain : Berdasarkan hasil penelitian yang di lakukan oleh saudari Miftaqul Qasanah (2012) tentang sistem implementasi website sebagai media informasi. Pembahasan meliputi implmentasi website secara menyeluruh. Dalam penelitian tersebut menyajikan pemesanan dan boking dan juga memberikan informasi yang terdapat di dalam rental mobil secara lengkap. Pembahasan keja praktek menggunkan konsep yang hampir sama namun dengan obyek penelitian yang berbeda dengan menambahkan fungsi website lebih luas bukan hanya sebagai media informasi dan promosi tapi terdapat juga paket paket tour yang telah di sediakan.

Berdasarkan penelitian yang dilakukan saudara Zezeto Da Costa Martins (2013) tentang rancang bangun dan implementasi sistem informasi sebagai media promosi dan pemesanan Muebel. Penelitian ini menjelaskan bagaimana dapat mengetahui berbagai macam barang yang di tawarkan sehingga pelanggan tidak harus datang ke toko tersebut. Masalahnya aplikasi tersebut hanya berfungsi untuk pemesan saja bukan untukpenjualan.

Hermanto (2014) membuat sistem informasi penyediaan layanan tour paket wisata bebasis web di PT Antacitra Trans. Pembuatan sistem tersebut bertujuan untuk mempermudah perusahaan dalam mempromosikan paket wisata dan juga customer bisa mengakses informasi, paket wisata dan customerdapat memberikan keluhan berupa kritik dan saran. Sistem sebelumnya hanya menggukankan brosur yang di bagikan serta pelanggan sering kali mengeluh karna kurangnya fasilitas informasi wisata. Sistem yang dirancang menghasilkan inputan berupa input data customer, input paket wisata, prosesnya yaitu kritik dan saran tanya jawab dengan pelanggan, info paket wisata, output yang di hasilkan berupa laporan paket wisata, laporan data pelanggan dan juga laporan kritik dan saran dari customer.

Metode Aprori ini berfungsi untuk mencari kombinasi item yang memenuhi syarat minimum dari nilai support dalam basis data. Nilai support sebuah tem diperoleh dengan menggunakan rumus berikut:

(Kusrini, Emha, 2013: 150-151) support(A)

$=$ jumlah transaksi mengandung $\mathrm{A} * 100 \%$

Total transaksi
Untuk mencari nilai support dari 2 item diperoleh dengan menggunakan Rumus : $\operatorname{support}(A, B)=P(A \cap B)$. $\operatorname{support}(A, B)$

$=\sum$ transaksi mengandung $A$ dan $B * 100 \%$ $\sum$ transaksi

Untuk mencari nilai support dari 3 item diperoleh dengan menggunakan rumus: support $(A, B$ dan $C)=P(A \cap B \cap C)$. support $(A, B$ dan $C)$ $=\sum$ transaksi mengandung A, B dan C $* 100 \%$ $\sum$ transaksi

Setelah semua pola frekuensi tinggi ditemukan, barulah dicari aturan asosiasi yang memenuhi syarat minimum untuk Confidence dengan menghitung confidence aturan asosiatif $\mathrm{A}$

$\rightarrow$ B. Nilai Confidence dari

aturan $\mathrm{A} \rightarrow \mathrm{B}$ diperoleh dengan rumus berikut: confidence $=\mathrm{P}(\mathrm{B} \mid \mathrm{A})$

$=\sum$ transaksi mengandung $A$ dan $B * 100 \%$ $\sum$ transaksi mengandung

A

Untuk menentukan aturan asosiasi yang akan dipilih maka harus diurutkan berdasarkan Support $\times$ Confidence. Aturan diambil sebanyak $\mathrm{n}$ aturan yang memiliki hasil terbesar.

\section{Metodologi Penelitian}

Metode yang digunakan penyusun dalam melakukan penelitian untuk mendapatkan data yang lengkap dan akurat, dilakukan teknik pengumpulan data dengan cara sebagai berikut:

Pengumpulan data dilakukan dengan metodemetode sebagai berikut :

a. Metode Observasi (Pengamatan

Langsung)

Observasi adalah pengamatan langsung suatu kegiatan yang sedang dilakukan oleh The Lombok Travel.

$b$. Metode Wawancara (Interview)

Wawancara (interview) dilakukan dengan cara mengumpulkan data secara tatap muka langsung antara penulis dengan orang yang diwawancarai yaitu pemilik The Lombok Travel Pertanyaan yang diajukan meliputi halhal yang berhubungan dengan tujuan destinasi wisata di daerah pulau lombok, sehingga data yang didapat lebih akurat.

c. Metode Dokumentasi

Dokumentasi merupakan suatu bentuk metode riset yang dilakukan dengan pengambilan beberapa contoh dokumentasi yang dapat berupa profil dan sejarah The Lombok Travel, informasi lokasi, ini dijadikan sebagai acuan 
maupun pertimbangan dalam penyusunan laporan Proyek Tugas Akhir.

\section{a. Analisis Sistem}

Kebutuhan akan informasi yang akurat dalam sistem akan mendorong suatu instansi untuk melakukan cara bagaimana memberikan pelayanan terbaik kepada penggunanya. Oleh karena itu, dilakukan penelitian untuk menganalis dan merancang sebuah sistem yang dapat menarik wisatawan agar liburan ke pulau lombok.

\section{b. Perancangan Sistem}

Perancangan sistem mencakup perancangan program berdasarkan hasil analisis yang telah dilakukan sebelumnya. Desain sistem juga meliputi kegiatan menerjemahkan hasil analisis sistem yang sudah berjalan dalam bentuk desain sistem penjualan dan pengolahan data paket wisata yang meliputi interface pengolahan data, alur program dan struktur data yang digunakan dan menghasilkan rancangan aristektural, rancangan data, rancangan procedural dan rancangan antar muka. Langakah yang dilakukan dalam perancangan sistem adalah perancangan basis data, perancangan proses dan perancangan interface sebelum nantinya akan diimplementasikan oleh The Lombok Travel.

\section{Hasil dan Pembahasan}

Berikut ini adalah pembahasan dan detail pemaparan dari masing - masing halaman web (web pages) dari Sistem informasi reservasi object wisata pada The Lombok Travel berbasis website. Dalam bagian ini akan dipaparkan screenshot dari masing-masing halaman Sistem informasi reservasi object wisata pada The Lombok Travel berbasis website beserta keterangan mengenai halaman tersebut.

Halaman ini berisikan menu login member. untuk lebih jelas dapat dilihat pada gambar 4.1
Don't Wait, Login now!

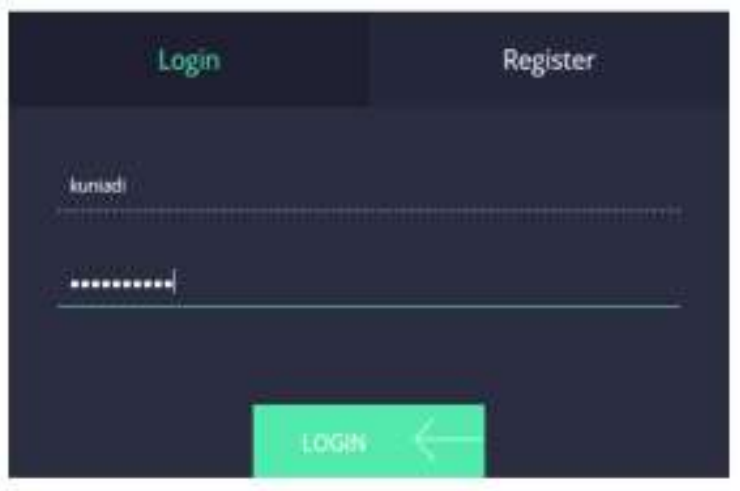

Gambar 4.1 Login Member

\section{Halaman Daftar Member}

Halaman ini berisikan kolom formulir data diri. untuk lebih jelas dapat dilihat pada gambar 4.2

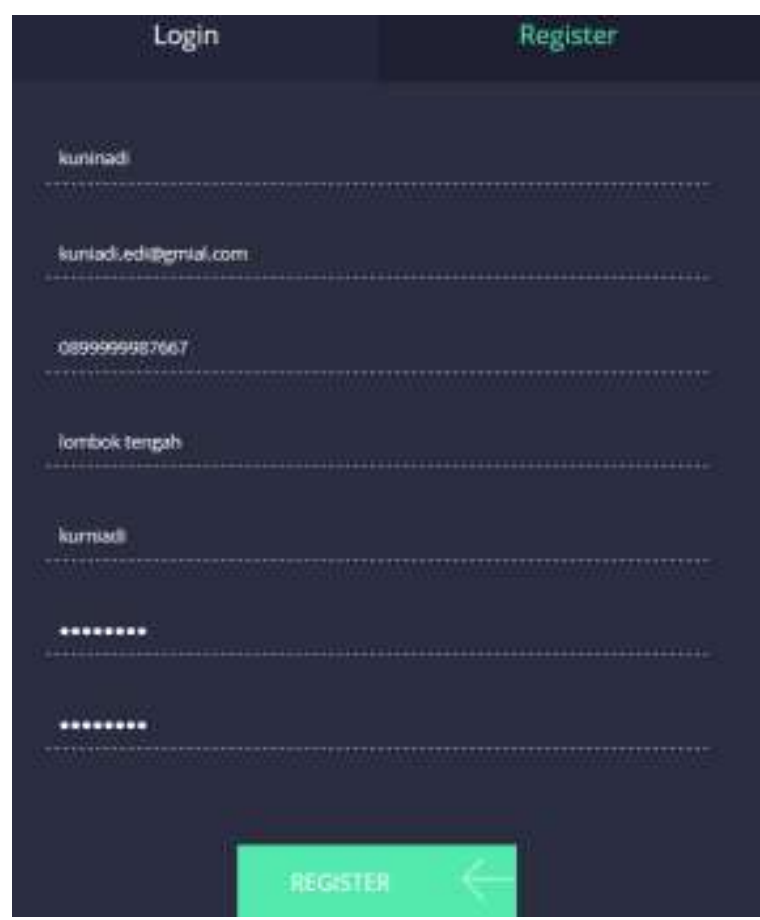

Gambar 4.2 Daftar Member

Halaman antarmuka member adalah halaman yang diusulkan sebagai ruang member untuk melakukan kegiatan pada sistem dari mulai melihat data paket, data transaksi sampai melakukan pemesanan paket. 


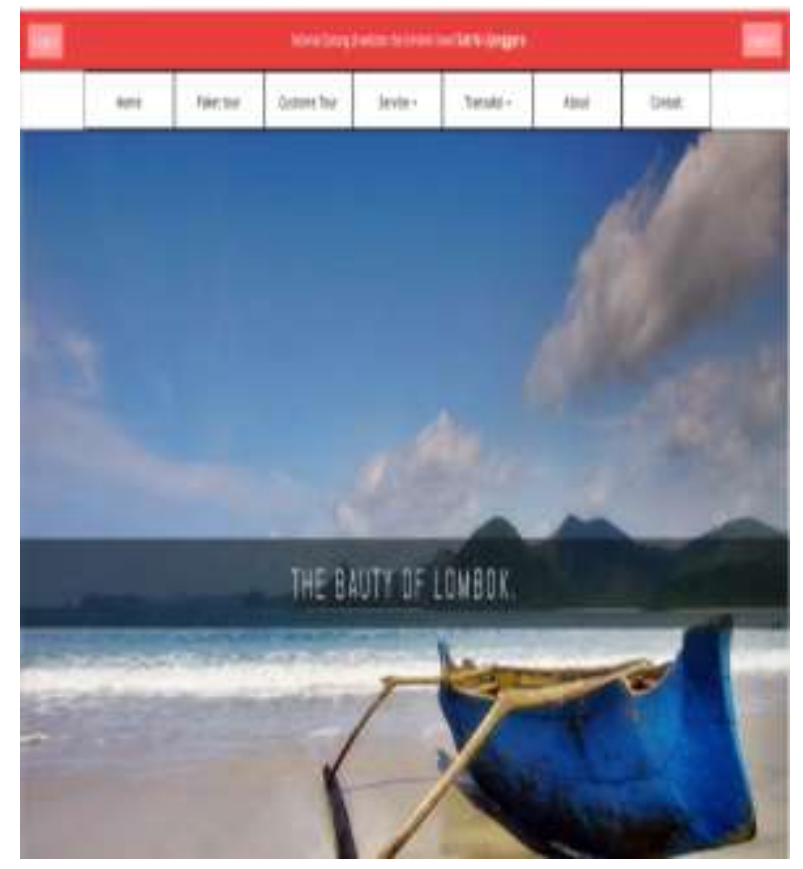

Gambar 4.3 Halaman Utama Member

\section{Halaman Login Admin}

Halaman ini berisikan menu login yang dapat diakses oleh admin, untuk lebih jelas dapat dilihat pada gambar 4.4

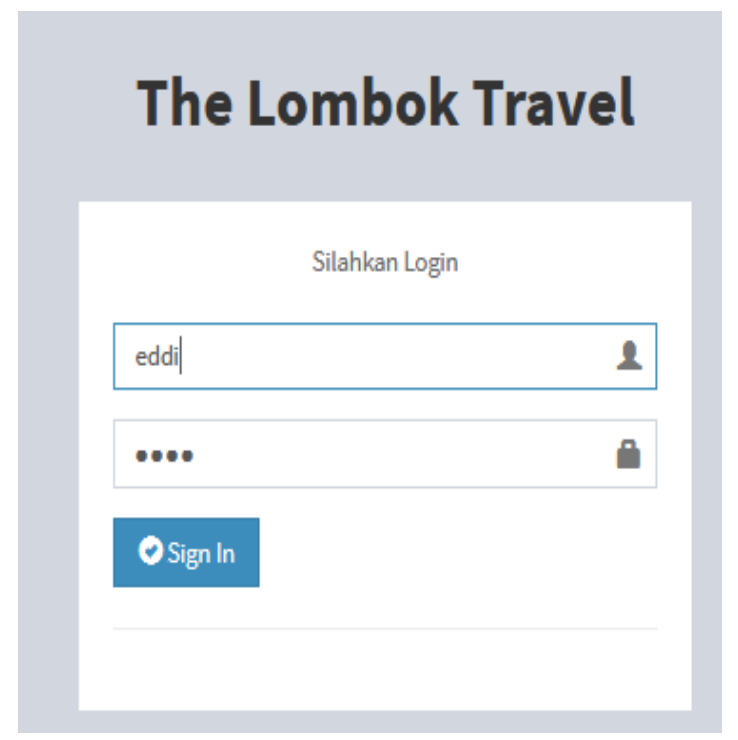

Gambar 4.4 Halaman Login Admin

Admin atau staf harus login terlebih dahulu agar mendapatkan hak akses, Setelah login admin dapat mengakses semua halaman, seperti input data paket, input pegawai, mengelola data pemesanan, melihat history pemesanan, melihat data member, data wilayah serta mengelola laporan.

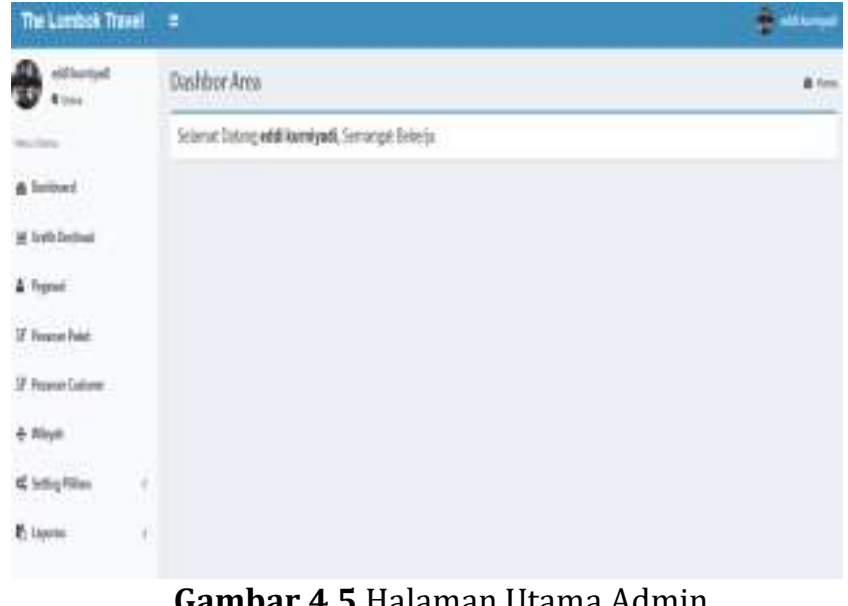

Gambar 4.5 Halaman Utama Admin

Kesimpulan Dari proses analisis, rancangan dan implementasi sistem yang telah dilakukan pada bab-bab sebelumnya, maka dapat diambil kesimpulan sebagai berikut:Sistem dibangun menggunakan bahasa pemprograman $P H P$ dan MySQL dan menghasilkan sistem yang dapat mempromosikan paket tour secara online. Sistem mempunyai fasilitas bagi member untuk melihat informasi paket tour, tujuan wisata, harga paket, pesan paket dan member bisa langsung melakukan pemesanan paket tour pada sistem karena sistem sudah bisa diakses secara online.

Untuk pengembangan sistem lebih lanjut, diberikan saran-saran sebagi berikut: Sistem memerlukan tambahan fitur berbasis Andoids dan tersedia di Apps Store agar mudah di download. Sistem tour ini hanya sebatas pulau Lombok, diharapkan kedepannya sistem tour ini bisa dikembangkan mengenai tujuan wisata yang ada di seluruh Indonesia. Sistem ini untuk kedepannya pemesanan dapat ditambahkan pemilihan mobil ynag bisa membedakan merk atau jenis mobil

\section{Daftar Pustaka:}

[1] Fatansyah. 2012. Basis Data. Bandung : Penerbit Informatika.

[2] Hermanto dedy. 2014. membuat sistem informasi penyediaan layanan tour paket wisata bebasis web di PT Antacitra Trans. Palembang.

[3] Kadir, Abdul., 2014. Pengenalan Sistem Informasi. Yogyakarta : Penerbit Andi

[4] Kismono, Gugup. 2013. Pengantar Bisnis. Yogyakarta : BPFE.

[5] Kusrini, Emha (2013). Algoritma Data. 
Yogyakarta: Andi Publisher.

[6] Martins, D,C,Z. 2013. rancang bangun dan implementasi sistem informasi sebagai media promosi dan pemesanan Muebel. Yogyakarta : Universitas Teknologi Yogyakarta

[7] Monaghan. 2013. The Ultimate Home-Based Travel Agent Expert. English : The Intrepid Traveler

[8] Nugroho, Bunafit., 2013. Dasar Pemprograman Web PHP-MySQL. Yogyakarta : GAVAMEDIA.
[9] Qasanah Miftaqul. 2012. sistem implementasi website sebagai media informasi. Yogyakarta : Universitas Teknologi Yogyakarta.

[10] Winamo, Sugeng., 2010. Jaringan Komputer dengan CTP. Bandung : Penerbit Informatika.

[11] Wiswakarma, Komang., 2009. Membuat Katalog Online dengan PHP dan CSS. Bali : LOKOMEDIA 